\title{
Emergency Radiology goes international
}

\author{
Ron Zagoria ${ }^{1}$
}

Published online: 20 October 2015

(C) American Society of Emergency Radiology 2015

With this issue of Emergency Radiology, we introduce an important new relationship for our journal. We announce that, in addition to our sponsoring organization, the American Society of Emergency Radiology (ASER), Emergency Radiology is now the official journal of the Society for Emergency Radiology-India. This is an exciting affiliation for our journal. As international collaborations have increased, our journal will benefit from a more global exposure and from additional subscribers. The Society for Emergency Radiology-India is a relatively new society with approximately 200 members, with plans to grow to a membership over 1000. This affiliation has come to fruition from the support of the leadership of our journal, ASER, and from Dr. Anjali Agrawal, an organizing member of the Society for Emergency Radiology-India, an ASER member, and a member of our Editorial Board. This affiliation will increase Emergency Radiology's influence in India where expertise and research in radiology is burgeoning. This is a geographic area of rapid growth in the subspecialty practice of emergency radiology. This affiliation will lead to increased number and diversity of submissions and thus improve the significance of our journal.
This will increase our understanding of medical journalism and emergency radiology issues in this important part of the world.

In addition to our new journal cover, there will be some journal enhancements related to this affiliation.

With upcoming issues, the following changes will take place:

- Journal subscriptions for all Society for Emergency Radiology-India members

- Mailing of Table-of-Content-Alerts (TOCA) to all Society for Emergency Radiology-India members through Springer

- $\quad 2$ journal pages/per issue for Society for Emergency Radiology-India news, meeting info, etc.

Many thanks to our publisher, Springer, and specifically to Dr. Ute Heilmann, who was instrumental in negotiating the terms for affiliation. I also want to recognize the leaders of the Society for Emergency Radiology-India whose work and vision have facilitated this affiliation.
Ron Zagoria

Ron.Zagoria@ucsf.edu

1 Department of Radiology and Biomedical Imaging, University of California, San Francisco, San Francisco, CA, USA 